\title{
Pengaruh Saluran Distribusi dalam Meningkatkan Volume Penjualan Petani Kacang Tanah di Desa Lamdesar Timur
}

\author{
${ }^{1}$ Paulus Laratmase, ${ }^{2}$ Karel Fredrik Gaus Basar Lusnarnera \\ ${ }^{1}$ Sekolah Tinggi Ilmu Ekonomi Saumlaki, laratmasep@gmail.com \\ ${ }^{2}$ Sekolah Tinggi Ilmu Ekonomi Saumlaki, karellusnarnera@gmail.com
}

\begin{abstract}
Abstrak
saluran distribusi merupakan serangkaian organisasi yang saling tergantung dalam mengambil keputusan yang tepat guna menentukan suatu barang/jasa untuk dapat digunakan atau dikonsumsi, demikian halnya bagi petani kacang tanah di Desa Lamdesar Timur yang belum bisa menentukan saluran distribusi secara optimal dalam meningkatkan volume penjualannya. Penelitian ini bertujuan untuk mengetahui apakah Saluran Distribusi langsung maupun saluran distribusi tidak langsung berpengaruh terhadap volume Penjualan. Penelitian ini dilakukan terhadap petani kacang tanah pada bulan Agustus - Oktober 2020 yang berlokasi di desa Lamdesar Timur Kabupaten Kepulauan Tanimbar. Metode survey digunakan dalam penelitian ini dengan sampel sebanyak 32 petani kacang tanah yang aktif melakukan produksi dan memasarkan kacang tanah. Pengumpulan data pada penelitian ini dilakukan melalui metode observasi dan wawancara dengan media kuisioner, serta data sekunder yang diperoleh terkait gambaran umum lokasi penelitian. Penelitian ini menjelaskan pengaruh kausal antara variabel penelitian $X$, dimana $X 1$ saluran Distribusi tidak langsung, $X 2$ saluran distribusi langsung dan $\mathrm{Y}$ volume penjualan melalui pengujian hipotesis. Teknik analisa data menggunakan regresi linear berganda $\mathrm{Y}=6.915+0.277 \mathrm{X} 1+0.545 \mathrm{X} 2$ untuk mengetahui jenis saluran distribusi yang digunakan. Hasil pengujian hipotesis berdasarkan kriteria penolakan Ho melalui pengujian nilai $\mathrm{t}_{\text {-hitung }}>\mathrm{t}_{\text {-tabel }}$ dengan tingkat signifikan $<0,05$, maka variabel yang berpengaruh signifikan terhadap volume penjualan adalah variabel X2 saluran distribusi langsung. Variabel saluran distribusi merupakan unsur penentu Dalam meningkatkan volume penjualan petani kacang tanah di Desa Lamdesar Timur.
\end{abstract}

Kata Kunci : Saluran distribusi, Volume penjualan 


\section{PENDAHULUAN}

Usaha pembangunan ekonomi pada umumnya, berkaitan erat dengan produktifitas tenaga kerja yang mengelolah Sumber Daya Alam. Otonomi daerah berdasarkan UU nomor 32 Tahun 2004, daerah diberi kewenangan dan peluang yang luas bagi penyelenggaraan fungsi pemerintahan, kecuali dalam bidang politik luar negeri, pertahanan, keamanan, Yustisi, moneter dan fiskal Nasional, serta agama. Untuk itu perlu adanya penajaman orientasi pembangunan yang berbasis pada potensi daerah guna dapat memberikan kontribusi bagi pembentukan PDRB Masing-masing daerah sehingga setiap daerah mampu menciptakan daya saing daerahnya masing-masing dengan tujuan untuk meningkatkan kesejahteraan masyarakyat setempat (Laratmase, Paulus. 2021).

Adanya perkembangan mengakibatkan pertumbuhan pada sektor usaha menengah, kecil dan mikro. Hal ini di tandai dengan hadirnya usaha- usaha nonindustri yang dapat menciptakan produk-produk yang memenuhi kebutuhan masyarakat. Pembangunan nasional menitikberatkan kepada sektor pertanian dan selanjutnya sektor pertanian bertujuan meningkatkan mutu dan hasil distribusi dan produksi, menigkatkan pendapatan serta taraf hidup petani yang memperluas lapangan kerja serta kesempatan kerja untuk menunjang pembangunan. Kebutuhan kacang tanah dari tahun ke tahun terus meningkat sejalan dengan bertambahnya jumlah penduduk, kebutuhan gizi masyarakat, diversifikasi pangan, serta meningkatnya kapasitas industri pakan dan makanan di Indonesia. Namun produksi kacang tanah dalam negeri belum mencukupi kebutuhan Indonesia yang masih memerlukan subsitusi impor dari luar negeri. Oleh sebab itu pemerintah terus berupaya meningkatkan jumlah produksi melalui intensifikasi, perluasan areal pertanaman dan penggunaan pemupukan yang tepat (Adisarwanto, 2000).

Pertumbuhan ekonomi juga merupakan salah satu dari indikator keberhasilan suatu proses pembangunan ekonomi yang terjadi pada suatu negara atau wilayah. Meskipun demikian, pertumbuhan ekonomi tidak identik dengan pembangunan ekonomi ( Malindar, B, 2021:08) 
Salah satu sektor yang diharapkan dapat meningkatkan kesejahteraan masyarakat yaitu sektor pertanian, karena masyarakat Indonesia yang sebagian besar hidup sebagai Masyarakat Agraris. pembangunan Kabupaten Kepulauan Tanimbar sebagai bagian integral dari pembangunan Nasional yang di arahkan untuk tetap menyatu dan berada pada arah kerangka pembangunan Nasional. Perbedaan berbagai faktor yang terdapat pada masingmasing daerah. Akibat dari perbedaan ini, kemampuan suatu daerah dalam mendorong proses pembangunan daerah tersebut menjadi berbeda, oleh karena itu tidaklah meng- herankan bilamana pada suatu proses pembangunan suatu wilayah biasanya terdapat wilayah maju dan wilayah terbelakang (Malindar, Balthasar. 2021)

Dalam kehidupan masyarakat Desa Lamdesar Timur, Kecamatan Tanimbar Utara, Kabupaten Kepulauan Tanimbar melangsungkan hidupnya dari pertanian, peternakan dan nelayan yang menjadi tolak ukur ekonomi masyarakat, walaupun di antara masyarakat ada yang telah memiliki perkerjaan lain misalnya PNS, pekerjaan bangunan dan lain-lain, namun masyarakat tetap melaksanakan kegiatan pertanian dalam hal ini berkebun, di dalamnya yang cukup menonjol yaitu berkebun Kacang Tanah.

Kacang tanah merupakan salah satu potensi lokal yang begitu dominan di Desa lamdesar timur dan dapat memberikan manfaat ekonomi bagi masyarakat di Desa tersebut apabila pemanfaatannya dijalankan dengan baik. Permasalahan yang sering muncul adalah strategi dalam mendistribusikan hasil produksi mereka guna meningkatkan volume penjualan, Saluran distribusi yang digunakan harus mendapatkan perhatian tersendiri, karena dengan tidak tepatnya saluran distribusi maka usaha penjualan tidak akan mencapai sasaran seperti yang diharapkan.

Saluran distribusi merupakan sebuah saluran yang dipakai oleh produsen untuk menyalurkan sebuah barang dari produsen ke konsumen. Sebuah perusahaan dapat menentukan penyaluran produknya melalui pedagang besar atau distributor, yang menyalurkannya kepedagang menengah atau subdistributor dan meneruskannya ke pengecer, yang menjualkan produk itu kepada pemakai atau konsumen. Bagi petani kacang tanah yang telah memiliki pembeli tetap setidaknya harus berusaha untuk 
mempertahankannya. Namun bagi petani yang belum maka mereka harus menentukan cara-cara yang tepat, dalam hal saluran distribusi untuk memasarkan produksinya. Berdasarkan uraian diatas maka dibuat sebuah rumusan masalah yakni adakah pengaruh saluran distribusi terhadap volume penjualan petani kacang tanah di Desa Lamdesar Timur.

Petani di Desa Lamdesar Timur, baik pengolahan maupun sistem bertaninya mempergunakan alat -alat yang masih bersifat tradisional, mengingat Desa tersebut tergolong salah satu desa $3 \mathrm{~T}$ di Kabupaten Kepulauan Tanimbar sehingga minimnya informasi tentang Distribusi akibat sangat terhambatnya jaringan internet yang mendukung, yang pada akhirnya akan berdampak pada volume penjualan.

Penelitian ini bertujuan untuk mengetahui seberapa besar pengaruh saluran distribusi terhadap volume penjualan petani kacang tanah di Desa Lamdesar Timur.

\section{TINJAUAN PUSTAKA}

Distribusi adalah saluran pemasaran yang dipakai oleh pembuat produk untuk mengirimkan produknya ke industri atau konsumen. Lembaga yang terdapat pada saluran distribusi adalah produsen, distributor, konsumen atau industri.

Suatu perusahaan dapat menentukan penyaluran produknya melalui pedagang besar atau distributor, yang menyalurkannya ke pedagang menengah atau subdistributor dan meneruskannya ke pengecer, yang menjual produk itu kepada pemakai atau konsumen. Saluran distribusi merupakan sebuah saluran yang dipakai oleh produsen untuk menyalurkan sebuah barang dari produsen ke konsumen.

Menurut Gitosudarmo Indriyo, saluran distribusi adalah sekelompok individu atau perusahaan yang mempunyai hak kepemilikan atas barang yang dipasarkan dan membantu dalam penyampaian hak kepemilikan barang atau jasa tersebut dari produsen kepada konsumen.

Bentuk saluran distribusi merupakan jalur yang dilalui oleh perpindahan hak milik atas barang yang di pasarkan untuk sampai ke tangan konsumen dengan melalui beberapa perantara. seperti halnya teori yang dikemukakan oleh Basu Swastha dan Irawan, Beberapa ahli mengemukaan teori pada dasarnya mempunyai prinsip yang sama, diantaranya : 
a. Bentuk saluran distribusi barang konsumsi, yaitu:

1. Produsen $\rightarrow$ KonsumenSering juga disebut saluran langsung karena tidak melibatkan pedagang besar.

2. Produsen $\rightarrow$ Pengecer $\rightarrow$ Konsumen

Dalam saluran ini, beberapa pengecer besar membeli secara langsung dari produsen. Ada juga beberapa produsen yang mendirikan toko pengecer untuk melayani penjualan.

3. Produsen $\rightarrow$ Pedagang besar $\rightarrow$ Pengecer $\rightarrow$ KonsumenSaluaran ini disebut juga saluran tradisional, dan banyak digunakan oleh produsen.

4. Produsen $\rightarrow$ Agen $\rightarrow$ Pengecer $\rightarrow$ KonsumenSelain menggunakan pedagang besar, produsen dapat pula menggunakan agen pabrik, makelar, atau perantara agen lainnya untuk mencapai pengecer, terutama pengecer besar.

5. Produsen $\rightarrow$ Age $\rightarrow$ Pedagang besar $\rightarrow$ Pengecer $\rightarrow$ Konsumen

produsen sering menggunakan agen sebagai perantara untuk menyalurkan barangnya kepada pedagang besar, yang kemudian menjualnya kepada toko-toko kecil. Agen yang terlibat dalam saluran distribusi ini terutama agen penjualan.
(Astri et al, 2017) menyatakan bahwa Volume Penjualan dapat didefenisikan sebagai barang yang terjual dalam bentuk uang untuk jangka waktu tertentu dan didalamnya mempunyai strategi pelayanan yang baik. Volume penjualan adalah tingkat penjualan yang diperoleh perusahan untuk periode tertentu dalam satuan (Unit,total atau rupiah).

\section{METODE PENELITIAN}

Penelitian ini dilaksanakan di Desa Lamdesar Timur, Kecamatan Tanimbar Utara, Kabupaten Kepulauan Tanimbar pada petani Kacang Tanah dari bulan Agustus - Oktober 2020. Penentuan lokasi dengan metode Purposive (sengaja) berdasarkan kriteria tertentu, dengan pertimbangan potensi kacang tanah yang begitu dominan dari hasil pertanian lainnya, dan petani kacang tanah di Desa tersebut masih berada dalam kondisi yang begitu tradisional, baik dalam segi produksi maupun pemasarannya.

Sumber data dalam penelitian ini menggunakan data Primer dan data Sekunder. Data Primer dikumpulkan dengan cara melakukan observasi dan wawancara langsung terhadap petani di lokasi penelitian dengan menyiapkan 


\section{ISSN : 2656-3363-VoL.3 NO.2. 2021}

Karaktristik Responden Jumlah/Jiwa

\section{A. Usia}

- $18-39 \quad 14$

- $40-59 \quad 15$

- >60 3

\section{B. Jenis Kelamin}

\begin{tabular}{|l|l|}
\hline - Laki-laki & 20 \\
\hline - Perempuan & 12 \\
\hline Pendidikan & \\
\hline - SD & 10 \\
\hline - SMP & 11 \\
\hline - SMA & 11 \\
\hline
\end{tabular}

kuisioner yang berisi pertanyaan dan memiliki skor yang tertera berdasarkan Skala Likert tentang saluran distribusi ( saluran disribusi langsung, saluran distribusi tidak langsung), dan Volume. Penjualan. Data sekunder yang digunakan adalah gambaran umum dari lokasi tempat dilaksanakannya penelitian dan data pendukung lain yang didapat dari Jurnal, Buku, Literatur lain dan juga internet.

Metode Analisis data dalam penelitian ini adalah deskriptif kuantitatif. Analisis deskriptif digunakan untuk menggambarkan data yang telah terkumpul dengan apa adanya, (sugiyono 2008), sedangkan analisis kuantitatif yang digunakan adalah analisis regresi linear berganda, karena dapat menganalisis pengaruh variabel bebas terhadap variabel terikat (Kuncoro 2009).
Populasi dari penelitian ini adalah petani yang melaksanakan usahatani kacang tanah. Sedangkan sampel (32 petani) ditentukan dengan cara stratified random sampling (Nazir.M, 2011), seperti yang ditampilkan tabel karakteristik responden dibawah ini berdasarkan Usia,jenis kelamin dan tingkat pendidikan dari responden.

Tabel. 1 Karakteristik Responden Sumber : Data Primer diolah, 2020

Parameter dari suatu hubungan fungsional antara sat variabel dependen dengan lebih dari suatu variabel ingin diestimasikan, maka analisis regresi yang dikerjakan berkenaan dengan regresi linear berganda (Nazir. M, 2011). Hubungan tersebut dinyatakan dengan bentuk persamaan dimana nilai dari suatu variabel atau yang diketahui dapat digunakan untuk menduga nilai dari variabel lain yang diketahui.

Hubungan antara satu variabel dependen dengan dua variabel independen, berbentuk: $\mathrm{Y}=\mathrm{a}+\mathrm{b} 1 \mathrm{X} 1+\mathrm{b} 2 \mathrm{X} 2+\ldots+\mathrm{e}$ 


\section{HASIL DAN PEMBAHASAN \\ Pengaruh Saluran Distribusi Terhadap Volume Penjualan Petani Kacang Tanah}

Untuk mengetahui apakah saluran distribusi berpengaruh terhadap Volume penjualan kacang tanah maka digunakan analisis Deskriptif kuantitatif sebagai berikut

\section{Analisi Pengujian Kualitas Data}

Pengujian validitas tiap butir digunakan analisis item, yaitu mengkorelasikan skor tiap butir dengan skor total yang akan merupakan jumlah tiap butir dengan skor total yang merupakan jumlah tiap skor butir (sugiyono 2109; 188). Item yang mempunyai korelasi positif dengan kriteriaum (skor total) serta korelasi yang tinggi, menunjukan bahwa item tersebut mempunyai validitas yang tinggi pula. Syarat minumum untuk dianggap memenuhi syarat adalah kala $\mathrm{r}=0.3$, kalau korelasi antara butir dengan skor total kurang dari 0,3 maka butir dalam instrumen tersebut dinyatakan tidak valid.(Sugiyono２019;189-190), seperti terlihat pada tabel dibawah ini.

\section{Uji Validitas}

Tabel 1. Uji Validtas

\begin{tabular}{|l|l|l|l|}
\hline Item & Pearson & $\mathrm{r}$ & Keterangan \\
\hline
\end{tabular}

\begin{tabular}{|c|c|}
\hline $\begin{array}{l}\text { Diman Y } \\
\text { a }\end{array}$ & $\begin{array}{l}\text { : Variabel dependen } \\
\text { (Volume Penjualan) }\end{array}$ \\
\hline $\mathrm{X}_{1}$ & $\begin{array}{l}\text { : Variabel independen } \\
\text { (Salluran distribusi tidak } \\
\text { langsung) }\end{array}$ \\
\hline $\mathrm{X}_{2}$ & $\begin{array}{l}\text { : Variabel independen } \\
\text { (Saluran distribusi }\end{array}$ \\
\hline a & $\begin{array}{l}\text { langsung) } \\
\text { : Nilai Konstanta }\end{array}$ \\
\hline $\mathrm{b}(1,2, \ldots)$ & : Nilai Koefisien regresi \\
\hline $\mathrm{e}$ & : Error \\
\hline
\end{tabular}

\begin{tabular}{|c|c|c|c|}
\hline Pertanyaan & Correlation & tabel & \\
\hline \multicolumn{4}{|c|}{ Disribusi Tidak Langsung (X1) } \\
\hline P1 & 0,553 & 0,30 & Valid \\
\hline P2 & 0,613 & 0,30 & Valid \\
\hline P3 & 0,598 & 0,30 & Valid \\
\hline P4 & 0,860 & 0,30 & Valid \\
\hline P5 & 0,581 & 0,30 & Valid \\
\hline P6 & 0,414 & 0,30 & Valid \\
\hline P7 & 0,521 & 0,30 & Valid \\
\hline P8 & 0,632 & 0,30 & Valid \\
\hline \multicolumn{4}{|c|}{ Distribusi Langsung (X2) } \\
\hline P1 & 0,575 & 0,60 & Valid \\
\hline $\mathrm{P} 2$ & 0,443 & 0,30 & Valid \\
\hline P3 & 0,555 & 0,30 & Valid \\
\hline P4 & 0,387 & 0,30 & Valid \\
\hline P5 & 0,459 & 0,30 & Valid \\
\hline P6 & 0,619 & 0,30 & Valid \\
\hline P7 & 0,495 & 0,30 & Valid \\
\hline $\mathrm{P} 8$ & 0,453 & 0,30 & Valid \\
\hline \multicolumn{4}{|c|}{ Volume Penjualan (Y) } \\
\hline Y1 & 0,618 & 0,30 & Valid \\
\hline $\mathrm{Y} 2$ & 0,636 & 0,30 & Valid \\
\hline $\mathrm{Y} 3$ & 0,702 & 0,30 & Valid \\
\hline $\mathrm{Y} 4$ & 0,374 & 0,30 & Valid \\
\hline Y5 & 0,601 & 0,30 & Valid \\
\hline Y6 & 0,489 & 0,30 & Valid \\
\hline Y7 & 0,402 & 0,30 & Valid \\
\hline Y8 & 0,382 & 0,30 & Valid \\
\hline
\end{tabular}

Sumber: Data diolah 2020

Berdasarkan tabel 1 diketahui pengujian validitas seperti yang telah di kemukakan, bila korelasi sama dengan 0,3 atau lebih maka dikatakan valid sehingga data dengan korelasi antara skor butir 1-8 
pada Variabel Distribusi Tidak Langsung (X1), Korelasi antara skor 1-8 pada butir pertanyaan Distribusi langsung (X2) dan korelasi antara skor butir 1-8 pada variabel Volume Penjualan(Y) korelasi antara buitir 1-8 sehingga pengujian tersebut ternyata setiap butir pertanyaan pada Variabel X1, $\mathrm{X} 2$ dan Y dinyatakan valid.

\section{Uji Reability}

\begin{tabular}{|l|l|l|l|}
\multicolumn{2}{c}{} & \multicolumn{2}{c|}{ Tabel 2. Uji Reabilitas } \\
\hline Variabel & $\begin{array}{l}\text { Cronbach } \\
\text { 's } \\
\text { Alpha }\end{array}$ & $\begin{array}{l}\text { Standar } \\
\text { Reliabilita } \\
\text { s }\end{array}$ & $\begin{array}{l}\text { Ketera } \\
\text { ngan }\end{array}$ \\
\hline $\begin{array}{l}\text { Disribusi } \\
\text { Tidak } \\
\text { Langsung } \\
\text { (X1) }\end{array}$ & 0,746 & 0,60 & $\begin{array}{l}\text { Reliab } \\
\text { el }\end{array}$ \\
\hline $\begin{array}{l}\text { Distribusi } \\
\text { Langsung } \\
\text { (X2) }\end{array}$ & 0,576 & 0,60 & $\begin{array}{l}\text { Tidak } \\
\text { Reliab } \\
\text { el }\end{array}$ \\
\hline $\begin{array}{l}\text { Volume } \\
\text { Penjualan } \\
\text { (Y) }\end{array}$ & 0,658 & 0,60 & $\begin{array}{l}\text { Reliab } \\
\text { el }\end{array}$ \\
\hline
\end{tabular}

Sumber : Data diolah 2020

Dari tabel.2 diatas maka di dalam pengujian Reability dimana pada variabel Disttribusi tidak langsung (X1) dalam hasil pengujiannya Cronbach's Alpha 0,746 > 0,60 disimpulkan bahwa intrumen penelitian yang digunakan untuk mengukur variabel ini hadal atau Reliabel. Variabel Distribusi Langsung (X2) Cronbach's Alpha 0,576 < 0,60 disimpulkam bahwa intrumen penelitian yang digunakan untuk mengukur variabel mendekati standar reabilitas namun instrumen penelitian ini hanya dapat di gunakan pada lokasi penelitian di daerah ini saja. Untuk Volume Penjualan 0,658 > 0,60 disimpulkan intrumen penelitian yang digunakan untuk mengukur variabel ini hadal atau Reliabel.

\section{Pengujian Asumsi Klasik}

\section{Uji Normalitas}

Dalam pengujian asumsi klasik pengujian normalitas untuk mengetahui data penelitian distribusi normal, karena dalam penelitian di mana dalam hasil penelitin dengan menggunakan norma P-plot dan Histogram serta One-Sample KolmogorovSmirnov Test

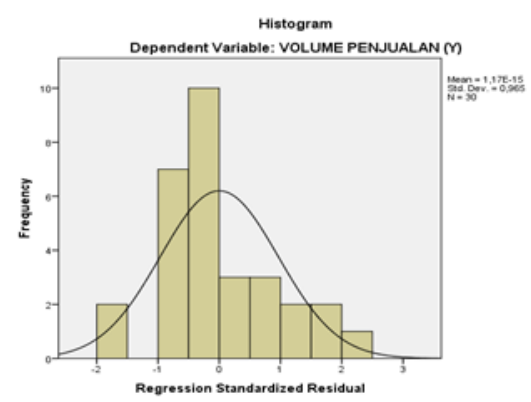

Gambar. 1

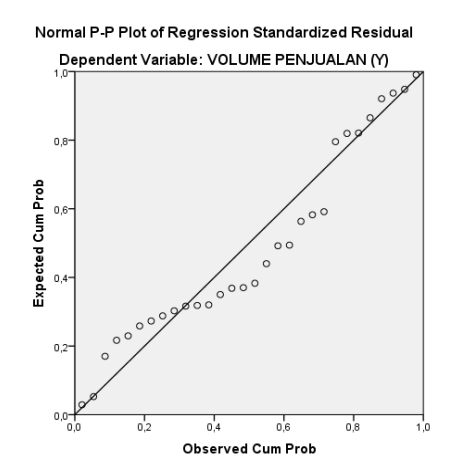

Gambar. 2

Berdasarkan gambar 1 dan 2 diatas dimana grafik histogram memberikan pola distribusi membentuk lonceng artinya data berdistribusi normal dan dalam pengujiam 


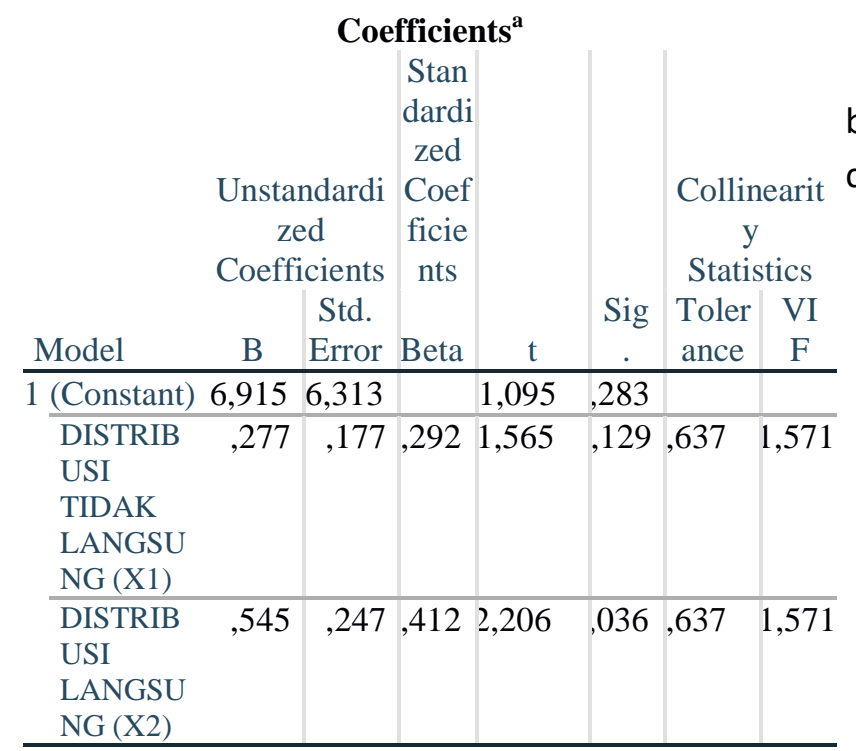

a. Dependent Variable: VOLUME PENJUALAN (Y) Chart dapat di lihat bahwa titik-tituk ploting yang terdapat pada gambar Normal P-P Plot

Of Regresssion Standardized Residual selalu mengikuti dan mendekati garis diagonalnya dapat disimpulkan bahwa nilai residualnya normal dengan demikian asumsi normalitas untk nilai residual dalam regresi linear sederhana dalam penelitian ini dapat terpadu.

One-Sample Kolmogorov-Smirnov Test

\begin{tabular}{lll} 
& & $\begin{array}{l}\text { Unstandardized } \\
\text { Residual }\end{array}$ \\
\hline $\mathrm{N}$ & & 30 \\
\hline Normal & Mean &, 0000000 \\
\cline { 2 - 3 } Parameters $^{\mathrm{a}, \mathrm{b}}$ & Std. Deviation & 1,96485337 \\
\hline Most Extreme & Absolute &, 155 \\
\cline { 2 - 3 } Differences & Positive &, 155 \\
\cline { 2 - 3 } & Negative &,- 109 \\
\hline Test Statistic & &, 155 \\
\hline Asymp. Sig. (2-tailed) &, $065^{\mathrm{c}}$ \\
\hline
\end{tabular}

a. Test distribution is Normal. b. Calculated from data.

c. Lilliefors Significance Correction.

Gambar. 3

NPar Tests

Pada gambar 3 diatas Untuk lebih memperjelas Hasil analisis uji Normalitas maka nilai Sig (2-tiled) diperoleh sebesar 0,65 artinya nilai tersebut lebih besar dari 0,05 maka dapat disimpulkan bahwa nilai residual berdistribusi Normal, maka hasil analisis ini dapat lanjut dalam uji regresi.

\section{Uji Regresi Linear Berganda}

\section{Regression}

Tabel 1. Uji T

Dari tabel 1 diatas dapat dilihat bahwa model regresi linear berganda dengan rumus regresi yang dipakai adalah sebagai berikut: $\quad \mathrm{Y}=6.915+0.277 \mathrm{X} 1+0.545 \mathrm{X} 2$ dengan pengujian hipotesis dimana kriteria penolakan Ho adalah dengan pengujian nilai $\mathrm{t}_{\text {-hitung }}>\mathrm{t}_{\text {-tabel }}$ dengan tingkat signifikan < 0,05. Sehingga dalam pengujian hipotesis pada hasil yang di peroleh adalah variabel (X1) dengan nilai signifikan $0.129>0.05$ dengan nilai $\mathrm{t}$ hitung $>\mathrm{t}$ tabel $: 1.565<1.697$ sehingga dapat disimpulkan bahwa variabel Distribusi 
Tidak Langsung (X1) tidak berpengaruh terhadap volume penjualan maka $\mathrm{Ha}$ ditolak Ho diterima sehingga hipotesis menyatakan tidak ada pengaruh variabel saluran distribusi tidak langsung (X1) terhadap variabel volume penjualan (Y).Sedangkan untuk variabel Distribusi Langsung (X2) dengan nilai $\mathrm{t}_{\text {hitung }}>\mathrm{t}_{\text {tabel }}$ : $2.206>1.697$ dengan nilai signifikan $0.036<0,05$, maka dapat disimpulkan bahwa variabel distribusi langsung (X2) secara parsial berpengaruh positif terhadap variabel volume Penjualan (Y).

Tabel 2. Uji Anova

Dari tabel 2 diatas hasil penelitin uji $\mathrm{F}$ secara silmultan $\mathrm{F}_{\text {hitung }}>\mathrm{F}_{\text {tabel dimana }}$ $\mathrm{dk}=\mathrm{n}-\mathrm{k}(30-2=28)$ dengan $9.012>3.34$ maka varian tidak homogen. Hal ini menunjukan bahwa adanya pengaruh Distribusi Langsung, Distribusi Tidak Langsung terhadap Volume penjualan.

Tabel 3

Koefisien Determinasi Model Summary ${ }^{b}$

\begin{tabular}{cc|c|c|c} 
Model & $\mathrm{R}$ & $\begin{array}{c}\mathrm{R} \\
\text { Square }\end{array}$ & $\begin{array}{c}\text { Adjusted R } \\
\text { Square }\end{array}$ & $\begin{array}{c}\text { Std. Error of } \\
\text { the Estimate }\end{array}$ \\
\hline 1 &, $633^{\mathrm{a}}$ &, 400 &, 356 & 2,036 \\
\hline
\end{tabular}
a. Predictors: (Constant), Distribusi Langsung (X2), Distribusi Tidak Langsung (X1)

b. Dependent Variable: Volume Penjualan (Y)

Berdasarkan tabel 3 diatas hasil pengujian model summary dimana $\mathrm{R}$ square 0,400 sehingga dapat di simpulkan $40 \%$ dipengaruhi oleh Variabel dalam penelitian ini, sedangkan $60 \%$ dipengaruhi oleh variabel lain.

\section{Kesimpulan}

Berdasarkan hasil Analisis dan pembahasan yang telah dikemukakan diatas, maka penelitian ini dapat disimpulkan sebagai berikut: Berdasarkan hasil pengujian regresi linear berganda dengan ketentuan rumus $\mathrm{Y}=6.915+0.277 \mathrm{X} 1+0.545 \mathrm{X} 2 \quad$ melalui

\begin{tabular}{lll|l|l|l}
\multicolumn{1}{c}{$\begin{array}{l}\text { Sum of } \\
\text { Squares }\end{array}$} & Df & $\begin{array}{l}\text { Mean } \\
\text { Square }\end{array}$ & F & Sig. \\
\hline $\begin{array}{l}\text { Model } \\
\text { Regres }\end{array}$ & 74,741 & 2 & 37,371 & 9,012 &, $001^{b}$ \\
\begin{tabular}{l} 
sion \\
\hline $\begin{array}{l}\text { Resid } \\
\text { ual }\end{array}$
\end{tabular} & 111,959 & 27 & 4,147 & & \\
\hline Total & 186,700 & 29 & & & \\
\hline
\end{tabular}

a. Dependent Variable: Volume Penjualan (Y)

b. Predictors: (Constant), Distribusi Langsung (X2), Distribusi Tidak Langsung (X1) pengujian hipotesis dimana kriteria penolakan Ho adalah dengan pengujian nilai t-hitung > t-tabel dengan tingkat signifikan $<0,05$. Sehingga dalam pengujian hasil yang di peroleh adalah variabel (X1) dengan nilai signifikan 0.129 $>0.05$ dengan nilai $\mathrm{t}$ hitung $>\mathrm{t}$ tabel : 1.565 < 1.697 dapat disimpulkan bahwa variabel Distribusi Tidak Langsung (X1) tidak berpengaruh terhadap volume 
penjualan maka Ha ditolak Ho diterima sehingga hipotesis menyatakan tidak ada pengaruh variabel saluran distribusi tidak langsung (X1) terhadap variabel volume penjualan (Y). Sedangkan untuk variabel Distribusi Langsung (X2) dengan nilai t hitung > t tabel : $2.206>1.697$ dengan nilai signifikan $0.036<0,05$, maka dapat disimpulkan bahwa variabel distribusi langsung (X2). secara parsial berpengaruh positif terhadap variabel volume Penjualan (Y). Hasil analisis uji F secara silmultan F hitung > F tabel dimana dk=n-k $(30-2=28)$ dengan $9.012>3.34$ maka varian tidak homogen. Hal ini menunjukan bahwa adanya pengaruh Distribusi Langsung, Distribusi Tidak Langsung terhadap Volume penjualan.

Berdasarkan penelitian yang dilakukan maka kami penulis sangat tertarik untuk dapat melanjutkan penulisan ini dengan menggunakan metode penelitian yang lebih akurat guna dapat menggali lebih dalam berbagai permasalahan dan fenomena-fenemena yang terjadi terhadap petani kacang tanah dengan saluran distribusi sebagai upaya dalam meningkatkan volume penjualan petani kacang tanah pada lokasi penelitian.

\section{Daftar Pustaka}

Gitosudarmo, I. (2014). Manajemen Pemasaran Cetakan Ketiga. Edisi Kedua. BPFE. Yogyakarta.

Kasman, H.(2015). Pengaruh Saluran Distribusi Terhadap Volume Penjualan Lafonte Pada PT Bentoro Adisandi Ivena Pekanbaru. Jurnal Ilmiah Ekonomi dan Bisnis (e-journal), 12(2).

Kuncoro M. (2009). Metode Riset untuk Bisnis dan Ekonomi, Erlangga, Jakarta

Laratmase, P. (2019). Klasifikasi Daerah Kabupaten/Kota Di Propinsi Maluku Berdasarkan Tipologi Klassen, https://thesiscommons.org/cns79/, Jurnal Sekolah Tinggi Ilmu Ekonomi Saumlaki Vol.1 No 2

Mariatun, I. L. (2017). Pengaruh Saluran Distribusi, Harga Dan Promosi Terhadap Volume Penjualan Pada Home Industri Tempe Putra Kl Kecamatan Socah Tahun 2016. Eco-Socio: Jurnal ilmu dan Pendidikan Ekonomi, 1(1), 31-44.

MTB dalam angka, (2016), tentang Pertanian, Badan Pusat Statistik Kabupaten MTB

Nazir M, (2011), Metode Penelitian- cet.7, Ghalia Indonesia, Bogor

Malindar, B. (2021, February 6). Penyebab Ketimpangan Wilayah di Provinsi Maluku. https://doi.org/10.17605/OSF.IO/KXD4Y.

Parengkuan, Greny Estherfien Olyvia. "The Influence of Distribution Channel Cost on Sales Volume in Sarana Tani Manado." Jurnal EMBA: Jurnal Riset Ekonomi, Manajemen, Bisnis dan Akuntansi 1.4 (2013).

Philip Kotler, kevin lane keller (2015), Manajemen Pemasaran, Erlangga, Jakarta

Setianingsih, Ajeng, et al. Pengaruh Saluran Distribusi Terhadap Volume Penjualan (Studi Kasus Pada PT. Sinar Sosro Cabang Rancaekek). http://jurnal.staialhidayahbog 
ISSN : 2656-3363 - VoL.3 NO.2. 2021

or.ac.id/index.php/ad/article/view/504.Jurn al Ekonomi dan Bisnis Islam, 2019, 3.2: 201-214.
Sugiyono. (2008). Metode Penelitian

Kuantitatif, Kualitatif dan $\mathrm{R}$ \& D. Bandung: Alfa Beta. 